\title{
From the Desk of the Editor-in-Chief Journal of Molecular Neuroscience: Frontotemporal Dementias with the Face to Future Research and Development
}

Published online: 6 October 2011

(C) Springer Science+Business Media, LLC 2011

I would like to thank Dr. Ghetti for his efforts in organizing the 7th International Conference on Frontotemporal Dementias, which turned out to be a wonderful event. The conference encompassed all aspects of frontotemporal dementias and brought together luminary contributors from various fields. The compilation of manuscripts in this special issue of the Journal of Molecular Neuroscience is the first of its kind and could not have come to fruition without the driving force and excellent insight, not to mention long hours of hard editorial work of Dr. Ghetti. He was helped by several dedicated reviewers including Dr. Jill Murrell, Dr. Rosa Rademakers, Dr. Salvatore Spina, Dr. Brandy Matthews, Dr. Michel Goedert, Dr. Michael Gold, Dr. Hanna Rosenmann, Dr. Andrew Kertesz, Dr. Shinsuke Fujioka and Dr. Emanuele Buratti. With the face to the future, based on the seminal findings of the involvement of tau in frontotemporal dementias there are ongoing preclinical developments targeting tau, progranulin and TDP-43. Most importantly, clinical trials are ongoing and planned focusing at the core of the diseases.

As we look at the scientific development in frontotemporal dementia with the current awareness of the importance of MAPT, PGRN, TDP-43 as pathogenetic elements, we will see a flourishing of preclinical and clinical trials targeting these abnormal proteins. Similarly, with the recent discovery of hexanucleotide repeat expansion in C9ORF72 as the cause of chromosome 9p21-linked ALS- frontotemporal dementia, we look forward to the next frontotemporal dementia meeting for the presentation of new data and disclosing new horizons.

Lastly, I would like to personally thank the contributors behind the scenes, Deb DeBusk, Liat Nissanov, and the dedicated Springer Staff.

Illana Gozes 